\title{
Chromium Recoil Implantation Into SAE 1020 Steel By Nitrogen Ion Bombardment
}

\author{
G. F. Gomes ${ }^{a)}$, M. Ueda ${ }^{a)}$, H. Reuther ${ }^{b)}$, E. Richter ${ }^{b)}$, and A. F. Beloto ${ }^{c)}$ \\ ${ }^{a)}$ Laboratório Associado de Plasma, LAP-INPE, São José dos Campos-SP, Brazil \\ ${ }^{b)}$ Forschungszentrum Rossendorf, FZR, Dresden, Germany \\ ${ }^{c)}$ Laboratório Associado de Materiais e Sensores, LAS-INPE, São José dos Campos
}

Received on 21 January, 2004; revised version received on 20 April, 2004

\begin{abstract}
SAE 1020 is a widely used plain carbon steel, as mortar reinforcement in buildings and small machine parts. But aside from good mechanical properties, its surface suffer from severe corrosion and high wear rate, due to modest hardness. Chromium (Cr) in excess of $12 \%$ in Fe alloys renders them resistant to several corrosive attacks. So we tried to introduce $\mathrm{Cr}$ in such amounts into the surface of that steel. $\mathrm{Cr}$ films were deposited by electron beam on SAE 1020 steel. Bombarding the $\mathrm{Cr}$ film either by nitrogen Plasma Immersion Ion Implantation (PIII) or nitrogen ion beam (IB), Cr atoms were recoil introduced into the Fe matrix. Normally, in the recoil process, heavy atoms are used, but in this set of experiments we used a relatively lighter atom, viz. nitrogen. SRIM simulation was used to show $\mathrm{Cr}$ atoms range in the steel matrix after being hit by nitrogen atoms. AES analysis showed ranges far beyond the calculated figures and in percentages above 13at. \%, enough to the purposes of these works. Preliminary corrosion results showed remarkable enhancement under corrosive attack.
\end{abstract}

\section{Introduction}

SAE 1020 construction steel is used frequently as mortar reinforcement and small machine parts[1-3]. But aside good surface properties as ductility, hardness and wear resistance, it is prone to severe corrosion. As the presence of Chromium $(\mathrm{Cr})$ in excess of $12-13 \%$ in Fe alloys, renders them resistance to several corrosive attacks, we tried to introduce such amount of $\mathrm{Cr}$ into the surface of this steel. $\mathrm{Cr}$ films were deposited by electron beam on SAE 1020 surface and then bombarding either by nitrogen Plasma Immersion Ion Implantation (PIII) or ion beam (IB) $\mathrm{Cr}$ atoms are recoil introduced into the steel matrix [4,5].

Numerical simulations were carried out using 2000.40 version of SRIM,[6] code, showing the range of $\mathrm{Cr}$ and $\mathrm{N}$ atoms in $\mathrm{Cr} / \mathrm{Fe}$ region, where the presence of $\mathrm{Cr}$ film was taken into account. These simulations showed that $\mathrm{Cr}$ atoms can be introduced in the steel surface by nitrogen ion recoil, confirmed by AES analysis. Preliminary corrosion analysis results showed great enhancement after such surface hybrid treatment.

\section{Experimental}

Before ion bombardment SAE 1020 steel samples were polished to $1 \mu \mathrm{m}$ with alumina powder and then covered with chromium film of several thicknesses, Fig. 1, in a $5 \mathrm{keV}$ electron beam device. Ion bombardment were performed using a $100 \mathrm{keV} \mathrm{N}^{+}$beam to doses of $2 \times 10^{17} \mathrm{~N} / \mathrm{cm}^{2}$ and $5 \times 10^{17} \mathrm{~N} / \mathrm{cm}^{2}$. In the case of nitrogen Plasma Immersion Ion Implantation, PIII, samples were bombarded using high voltage pulses at $40 \mathrm{kV}$ and pressure of $8 \times 10^{-2}$ mbar in a nitrogen plasma, to doses about $3 \times 10^{17} \mathrm{~N} / \mathrm{cm}^{2}$. Plasma Immersion Ion Implantation is a novel technique, used as a means to improve surface properties of materials like metals, semiconductors and insulators. In this process, a sample is immersed in suitable plasma and then repetitively bombarded with high negative voltage pulses. Under the negative pulses, positive ions are extracted from plasma and then implanted in the surface of the sample. As in other plasma immersion treatment, all the exposed sample surfaces are simultaneously treated [7-9]. Ion implantation introduces beneficial effects into the treated surface. Among these effects, are enhancements in hardness, corrosion resistance, wear and in fatigue life. Some of these effects are due to formation of compounds of implanted ion and surface components and other due to lattice damage.

SRIM simulation showed $\mathrm{Cr}$ atoms introduced into steel surface after $\mathrm{N}$ recoil, at several ion energies. Auger Electron Spectroscopy (AES) measurements were applied to elemental profiling.

\section{Results}

SRIM simulation of nitrogen ion bombardment on Cr film, showing that the latter can be introduced into the iron matrix, as can be seen in the Fig. 2, were confirmed by AES results. The energy of nitrogen ion beam at $100 \mathrm{keV}$ seems to be large enough to make the ion $\mathrm{N}^{+}$to cross the $\mathrm{Cr}$ film, and despite of a $30 \% \mathrm{Cr}$ content measured in the region just beneath the interface between the $\mathrm{Cr}$ film and the steel, $\mathrm{Cr}$ atoms lie in a very thin layer, less than $9 \mathrm{~nm}$, as can be seen 


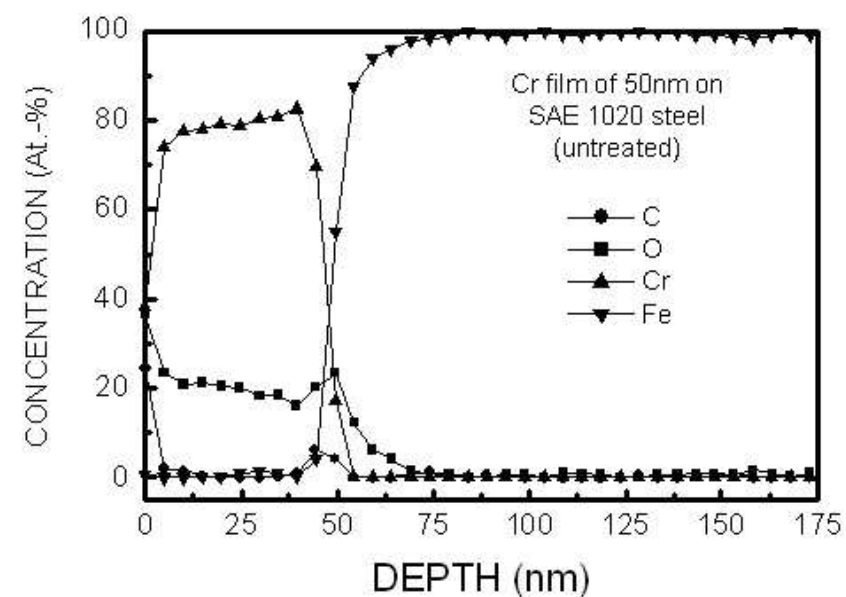

Figure 1. AES profile of a $50 \mathrm{~nm}$ Cr film on SAE 1020, deposited by a $5 \mathrm{keV}$ electron beam.

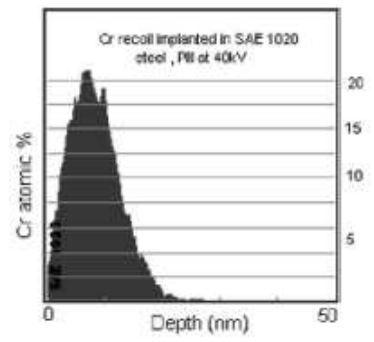

(a)

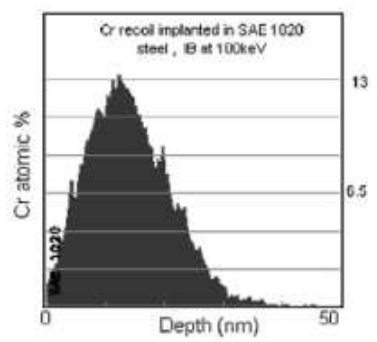

(b)
Figure 2. Theoretical depth profile of $\mathrm{Cr}$ atoms in SAE 1020, after Nitrogen recoil at (a) $40 \mathrm{kV}$ (PIII) and (b) $100 \mathrm{keV}$ (IB), beyond the $50 \mathrm{~nm}$ original $\mathrm{Cr}$ film.

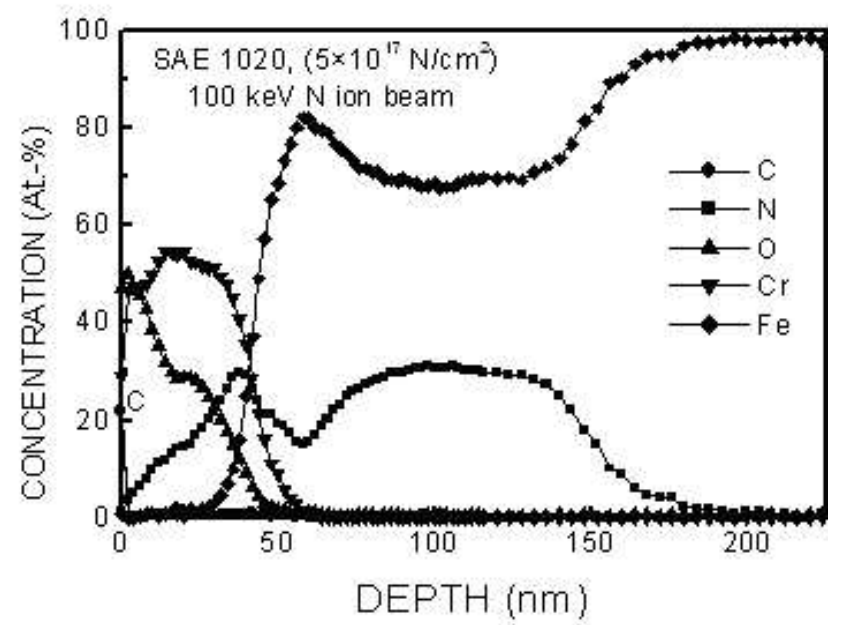

Figure 3. AES depth profile of the Cr into SAE 1020 matrix, after Ion Beam bombardment by $\mathrm{N}^{+}$at $100 \mathrm{keV}$ energy.

in the Fig. 3. The best $\mathrm{Cr}$ implantation was attained using $\mathrm{Cr}$ film of $50 \mathrm{~nm}$ and PIII at $40 \mathrm{kV}$, with percentages over $13 \%$
$\mathrm{Cr}$ at the surface in a layer ranging over more than $90 \mathrm{~nm}$, as seen in Fig. 4. Oxygen appears as impurity in the modified layer, probably coming from the pumping system. Preliminary corrosion tests indicated remarkable increase in the SAE 1020 resistance under corrosive medium attack, even in the case of IB, that produced a modest $\mathrm{Cr}$ enriched layer in the treated samples and great amount of $\mathrm{Cr}$ remaining in the original film.

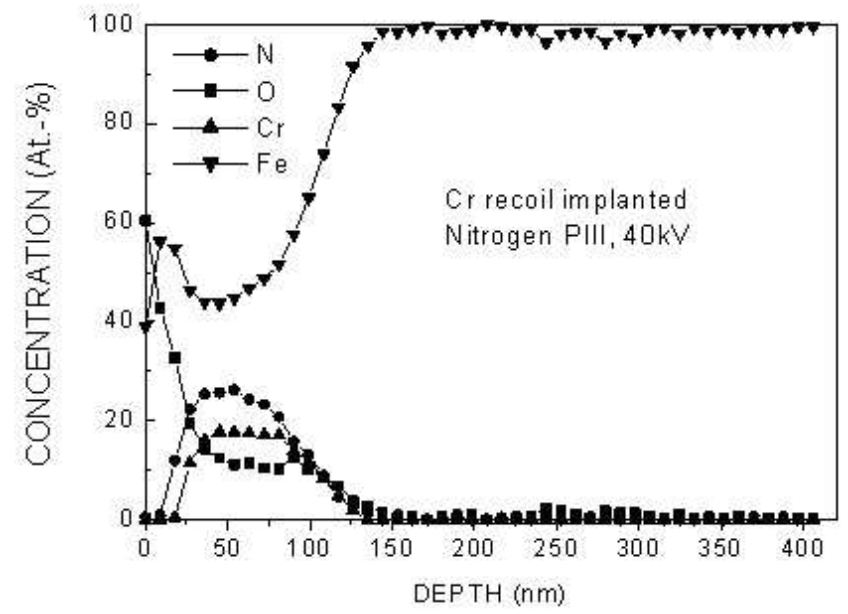

Figure 4. AES depth profile of the Cr into SAE matrix, after $\mathrm{N}$ Plasma Immersion Ion Implantation bombardment at $40 \mathrm{kV}$.

In the case of PIII, the modified layer showed good uniformity, with a maximum of $17 \%$ at., ranging to about 90 $\mathrm{nm}$. Almost all the $\mathrm{Cr}$ film was implanted in the steel surface. By another side, IB implantation presented an irregular profile, with a maximum of $30 \%$ at., going into the surface for about only $10 \mathrm{~nm}$, with a large part of the original film remaining on the steel surface.

Corrosion test showed good performance of the PIII treated sample. The IB treated sample showed some enhancement over the reference and the only $\mathrm{Cr}$ film treated sample showed no modification on the corrosion character as compared to the non-treated reference.

\section{Conclusion}

To produce a Cr-rich layer on the surface of construction steel, aiming to enhance its corrosion resistance, we deposited Cr films of several thicknesses on SAE 1020 steel surface. Then, we bombarded the film either by Nitrogen Plasma Immersion Ion Implantation, at $40 \mathrm{kV}$ or by Ion Beam, at 50 and $100 \mathrm{keV}$. Nitrogen hitting on $\mathrm{Cr}$ atoms caused them to penetrate the iron matrix.

Computer simulations showed that by bombarding a $\mathrm{Cr}$ film with energetic nitrogen ions, it is possible to implant some $\mathrm{Cr}$ atoms by recoil process.

\section{Acknowledgements}

This work is partially funded by FAPESP, to whom G.F. Gomes thanks a post-doctoral fellowship. 


\section{References}

[1] R. Capozucca, Construction and Building Materials, 9(5) 295 (1995).

[2] C. Andrade, C. Alonso, Constr. and Build. Mat. 15, 141 (2001).

[3] H. Agerskov, Journal of Constructional Steel Research, 53, 283 (2000).

[4] A. Anders, S. Anders, I. G. Brown, and K. M. Yu. Nucl. Instr. and Meth. in Phys. Res. B, 102, 132 (1995).
[5] Z. - C. Wu, Y. - L. Liu, and M. - C. Chen, Thin Solid Films, 358, 180 (2000).

[6] J. F. Ziegler, J. P. Biersack, and U. Littmark, The Stopping and Range of Ions, in Matter, v.1, Pergamon, New York, 1985

[7] M. Ueda, L. A. Berni, G. F. Gomes, A. F. Beloto, E. Abramof, and H. Reuther, J. Appl. Phys., 86, 4821 (1999).

[8] M. Ueda, G.F. Gomes, E. Abramof, and H. Reuther. Nucl. Instr. and Meth. in Phys. Res. B, 206, 749 (2003).

[9] G. F. Gomes, M. Ueda, and H. Reuther, J. Appl. Phys. 94, 5379 (2003). 